\title{
Prediction of channel sandbody distribution in the lower section of Sifangtai Formation at the southern end of Chang Placanticline in Songliao Basin
}

\author{
Wenping Zhu ${ }^{1}$, Axiang $\mathrm{Sun}^{2}$, Xiaowen $\mathrm{Liu}^{1,{ }^{*}}$, Shangming Shi ${ }^{1}$, and Huabin $\mathrm{Wei}^{1}$ \\ ${ }^{1}$ School of Earth Sciences, Northeast Petroleum University, Daqing, Heilongjiang Province, China \\ ${ }^{2}$ Qing xin oil development limited liability company, China
}

\begin{abstract}
The channel sand bodies in the lower section of the Sifangtai Formation in the Songliao Basin are rich in uranium resources. The development of channel sand body distribution prediction is of great significance for guiding the exploration of sandstone-type uranium deposits. In this study, the wave-indicated inversion technology was used to predict the thickness of the sand body, the root mean square amplitude attribute was used to identify the plane shape of the river channel, and the seismic facies analysis and tracking technology of the section was used to identify the channel period and finely describe the channel distribution. The results show that there are two stages of channel sand bodies in the lower part of Sifangtai Formation, and the sand bodies are distributed in a wide range. The maximum thickness of single stage sand bodies is about $15 \mathrm{~m}$, with an average of 8 meters. The thickness of the sand body where the two phases of the river are superimposed is the largest, up to $28 \mathrm{~m}$, which is a favorable ore-bearing location revealed by current exploration.

Keywords: Sifangtai formation; Sandstone-type uranium deposit; Sand body inversion; Attribute prediction.
\end{abstract}

\section{Introduction}

Sandstone-type uranium deposits are the main type of uranium exploration in my country. In recent years, important prospecting breakthroughs have been made in the Daqing Placanticline and its surrounding areas in the northern Songliao Basin $[1]$, and industrial uranium ore bodies and uranium mineralization points have been discovered in the channel sand bodies of the lower section of the Sifangtai Formation. On the basis of previous studies, through statistical analysis of the natural gamma values reflected by thousands of wells in the Songliao Basin, it is proved that the Sifangtai Formation has obvious uranium anomalies. However, the Sifangtai Formation is relatively shallow and is not the main horizon for oil and gas exploration, so there are few studies. In this study, the use of waveform indicating inversion technology and seismic facies analysis technology is used to predict the channel sand bodies in the lower section of Sifangtai Formation, and to

* Corresponding author: 2467681521@qq.com 
predict its favorable areas, with a view to providing directions for sandstone-type uranium exploration.

\section{Geological profile}

The study area is located at the southern end of Daqing Changyuan (Fig 1). The stratum of Sifangtai Formation is the stratum deposited at the beginning of the shrinking period, and the faults are relatively undeveloped. The gentle slope and structural "skylight" formed are one of the favorable conditions for uranium mineralization. The Sifangtai Formation is dominated by river-lacust deposits. The industrial uranium deposits are mainly distributed in the sandstone of the Datao channel in the lower section of the Sifangtai Formation, in a plate-like distribution. Based on clarifying the structural and sedimentary characteristics of the Sifangtai Formation, this paper focuses on the distribution characteristics of channel sand bodies in the lower section of the Sifangtai Formation.

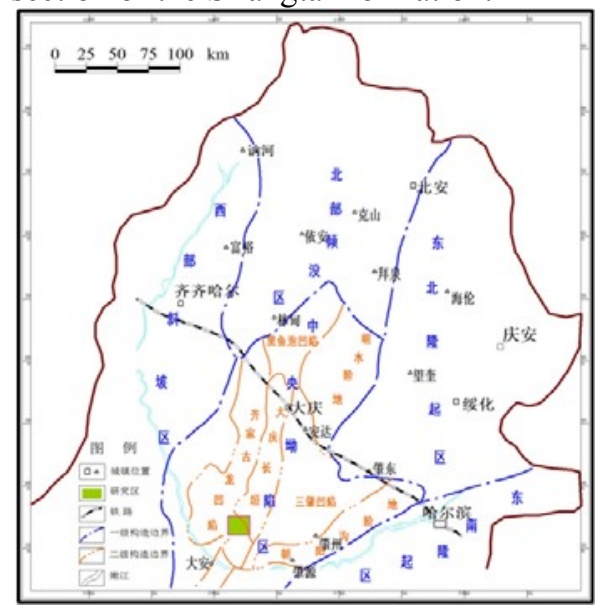

Fig. 1. Location map of tectonic units in the study area.

\section{Sand body inversion}

Waveform indicator inversion is an inversion method that uses the lateral changes of seismic waveforms instead of variograms to characterize the degree of spatial variability of the reservoir, which conforms to the laws of sedimentary geology ${ }^{[2]}$. The use of waveform indication inversion requires data processing to provide data support for the inversion. Due to the error in the acquired logging data, in order to minimize the influence of the error, the acquired curve must be processed before the seismic inversion, and then the subsequent inversion work must be performed.

\subsection{Optimization of sensitive parameters}

Use the histogram method to compare the ability of each curve to identify lithology (Fig 2). Through the comparison and analysis of different curve histograms, it can be seen that the acoustic time difference curve and the wave impedance curve cannot distinguish sand and mudstone, while the resistivity curve and the spontaneous potential curve can distinguish fine sandstone and mudstone to a certain extent, but the grain size is between the two The siltstone cannot be distinguished. In comparison, the resistivity curve has the best effect in distinguishing sand and mudstone, so it is used as the characteristic curve for constrained 
inversion.

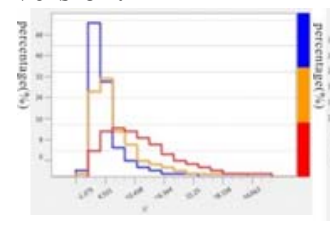

(a) Resistivity curve

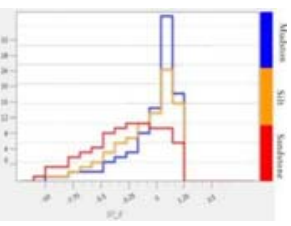

(b) Spontaneous potential curve

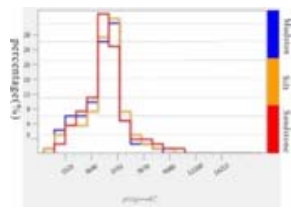

(c) Wave impedance curve

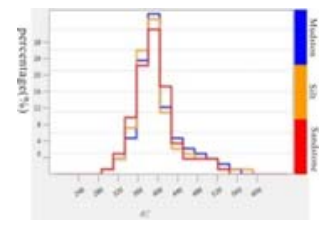

(d) Acoustic time difference curve

Fig. 2. Different curves to distinguish lithology recognition ability.

\subsection{Resistivity curve constraint participation inversion}

Due to the large range of resistivity value, the resistivity curve of the Sifang station group is logarithmically processed to obtain the LgR curve. Using the LandMark software, with the $\mathrm{LgR}$ curve as the constraint, according to the characteristics of the seismic waveform, the high-frequency common structure from the well drilled was used as the initial model to realize the well-seismic coordinated inversion to obtain the resistivity body, which is used to predict the sand body (Fig3).

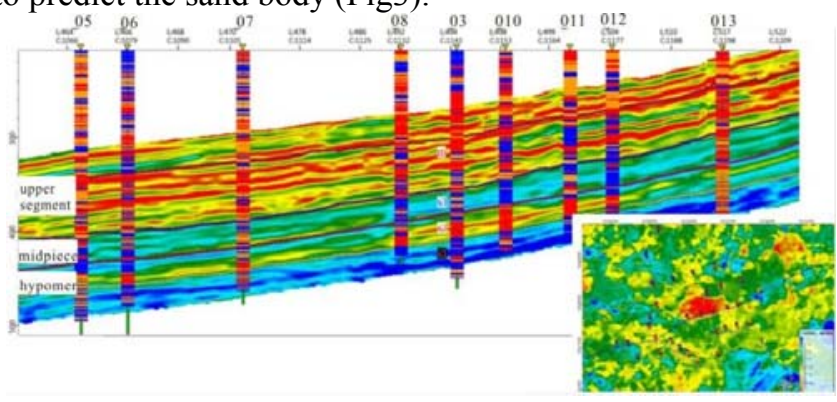

Fig. 3. Inversion profile of Sifang Formation.

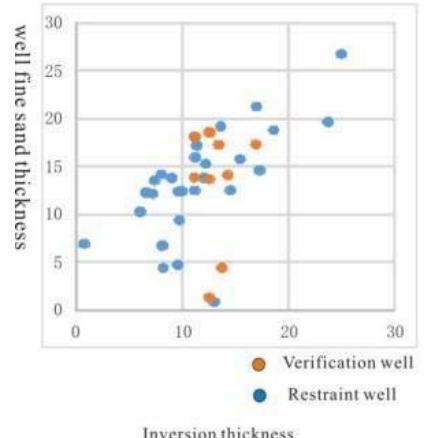

Inversion thickness

Fig. 4.Inversion fit analysis graph.

Compared with the inversion profile and logging lithology, it can be seen that the inversion result is better. The results show that the inversion results have a high accuracy rate, and can identify fine sand larger than 6 meters, with an average relative error of $-16.6 \%$ (Fig 4). Fine sand less than 6 meters is greatly affected by the vertical accuracy of seismic data and siltstone, and the predicted value is generally higher. Judging from the sand body thickness map, the sand bodies in the lower part of Sifangtai Formation are widely distributed, with a maximum thickness of $28 \mathrm{~m}$, generally $9 \mathrm{~m}$. Since the bank subfacies also have sand bodies, but they are not the main facies belts for uranium enrichment, it is necessary to describe the distribution range of channel sand bodies on the basis of sand body thickness prediction.

\section{River spread identification}

In the seismic data, the bottom surface of the channel sand body shows strong amplitude characteristics. Through the seismic reflection tracking of the profile, the channel sand body is identified and characterized. 


\subsection{The description of the plane shape of the river}

Seismic attributes can reflect specific physical and geological connotations. Through the extraction and comparison of the attributes, the well verification and the observation of the sand body plane morphology, it is believed that the root mean square amplitude (RMS) attribute is the most consistent with the well, and the channel sand body morphology characteristics are clear, which can show the sand body well. The planar distribution characteristics of the volume. Therefore, the root mean square amplitude attribute is selected to describe the plane distribution of the river channel [3].

\subsection{Sectional seismic facies analysis and tracking of river channels}

From the logging curves and inversion profiles, there are two stages of channels developed in the lower part of the Sifangtai Formation. Due to the low vertical resolution of seismic data, it is difficult to distinguish the two stages of channels by attributes (Fig 5). In order to accurately describe the distribution characteristics of the two-stage river channels, the technical means of section seismic facies analysis and tracking [4] are used to identify and describe the channel features, thereby improving the accuracy of channel sand body prediction.

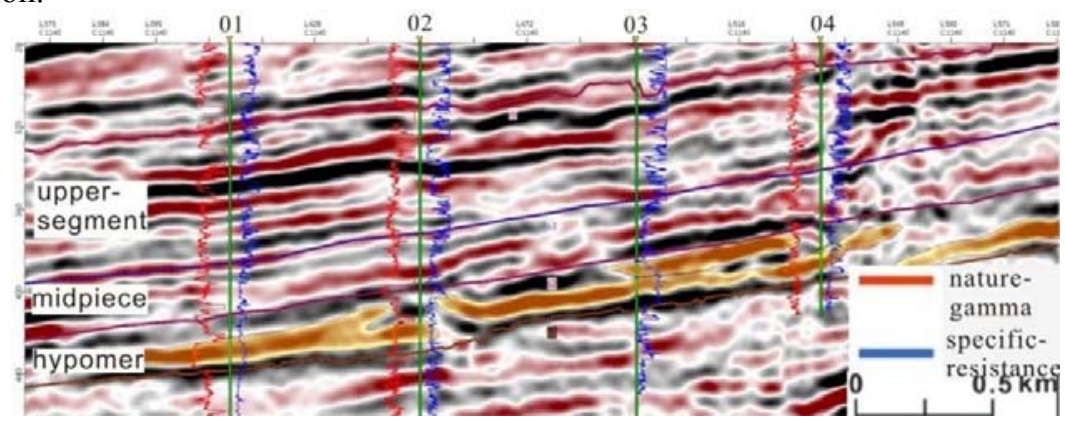

Fig. 5. Recognition of seismic facies of profile channel.

Through accurate logging calibration, the reflection characteristics of the channel sand bodies in the lower section of the Sifangtai Formation on the seismic profile are identified. The results show that the river channel shows strong amplitude, negative phase, straight and continuous and stable reflection characteristics, while the non-river channel shows weak amplitude discontinuity. This reflection feature is used as the seismic identification mark of the river channel sand body, and then through the three-dimensional continuous tracking technology, the plane shape of the two-stage river channel is finally depicted (Fig 6 and Fig $7)$.
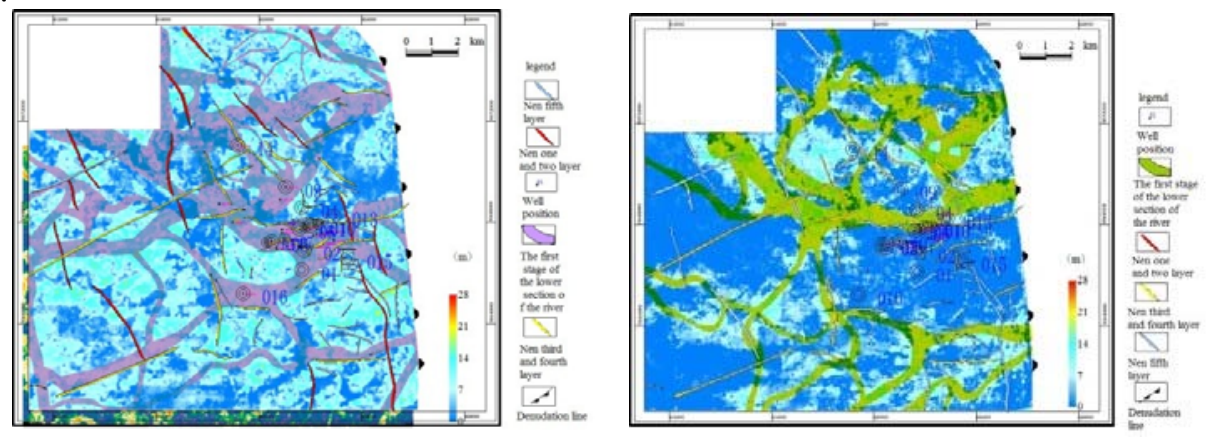

Fig. 6. The first phase of the river. Fig. 7. The second phase of the river. 


\subsection{The distribution characteristics of the two phases of the river}

The first stage of the river channel in the lower part of Sifangtai Formation is relatively well-developed. The sand body has a maximum thickness of about $15 \mathrm{~m}$ and an average of about 9 meters. The channel width is up to $1500 \mathrm{~m}$, generally around $600 \mathrm{~m}$. In the second stage, the degree of development of the river channel is reduced. The maximum sand body thickness is about $11 \mathrm{~m}$, and the average is about 6 meters. The channel width is the largest $1000 \mathrm{~m}$, generally around $400 \mathrm{~m}$. The two phases have a vertical stacking relationship. The thickness of the sand body at the overlap point is the largest, up to $28 \mathrm{~m}$. Due to the large thickness of the sand body and good reservoir physical properties, it can provide a favorable reservoir space for the enrichment of sandstone-type uranium deposits. Revealed favorable ore-bearing location.

\section{Conclusion}

This paper uses the waveform indicator inversion technology to predict the sand body in the lower part of the Sifangtai Formation in a certain block, which can effectively identify fine sand with a thickness of more than 6 meters, and the prediction accuracy rate is about $83.4 \%$. Using root-mean-square amplitude attributes and seismic facies profile characteristics, the distribution of the two phases of the river channels in the lower section of the Sifangtai Formation was traced, and the distribution of sand bodies in the study area was predicted.

\section{Acknowledgements}

Financial support. This research was funded by the Youth Fund Project of Northeast Petroleum University (2018QNL-48)

\section{References}

1. XING Zuochang,QIN Mingkuan,LI Yan,GUO Qiang,ZHANG Yang,Jia Licheng,Xiao Jing. Stratigraphic architecture, sedimentary filling and uranium prospecting direction of upper Cretaceous strata, northeastern Songliao Basin [J]. Geology in China, https://kns.cnki.net/kcms/detail/11.1167.P.20200803.1808.004.html.

2. YUE Lijun,QIAN Yanling. Prediction of the narrow-thin reservoir based on seismic waveform indication inversion technology[J]. Petroleum Geology \& Oilfield Development in Daqing, 1000-3754 ( 2020) 05-0135-06.

3. Yu Shuang Hu; Si Miao Zhu. Predict Channel Sand Body Distribution Characteristics of South Eighth District Based on RMS Amplitude Attributes \& Frequency Division[J]. Advanced Materials ResearchVolume 2482, 2013. PP 404-407

4. WAND Yin, LI Wencheng, C H EN Huixia, HE Hongbing. Fine characterization technology and application of reefbeach seismic fades in the third member of maokou formation in YB area[J]. COMPUTING TECHNIQUES FOR GEOPHYSICAL AND GEOCHEMICAL EXPLORATION, 1001-1749(2020)06-0695-09 